\title{
LA EXPANSIÓN DEL DERECHO DEL TRABAJO. WEIMAR Y SUS ANTEPASADOS*
}

\author{
THE EXPANSION OF LABOR LAW. \\ WEIMAR AND ITS ANCESTORS \\ L'ÉLARGISSEMENT DE LA LÉGISLATION DU TRAVAIL. \\ WEIMAR ET SES PRÉDÉCESSEURS
}

\author{
José Luis UGARTE CATALDO*
}

RESUMEN: La derrota de la perspectiva revolucionaria y concejil del movimiento obrero permitirá la expansión del derecho del trabajo, que será entendido como una forma eficaz de integración social de los trabajadores en las sociedades capitalistas fuertemente tensionadas a principios del siglo veinte. Clave en esa expansión será el denominado Laboratorio Weimar, donde confluirán un puñado de autores que ensayarán las fórmulas jurídicas y políticas que serán las bases del desarrollo del derecho del trabajo, y que, como sostendremos en estas líneas, expresan una perspectiva filosófica sobre la relevancia existencial del trabajo y sobre la acción política para su emancipación, con innegables influencias de Hegel, Marx y Bernstein.

Palabras clave: derecho del trabajo, consejo obrero, laboratorio Weimar, filosofía del trabajo.

ABSTRACT: The defeat of the revolutionary and council perspective of the workers movement will allow the expansion of Labor Law, which will be understood as an effective form of social integration of workers in capitalist societies strongly stressed at the beginning of the twentieth century. The so-called Weimar Laboratory will be essential in this expansion, since a group of authors will test the legal and political

* Recibido el 11 de enero de 2021 y aceptado para su publicación el 15 de marzo de 2021.

** Doctor en derecho y profesor de derecho del trabajo, Universidad Diego Portales. 
formulas that will be the bases of the development of Labor Law, and that, as we will argue in these articles, express a philosophical perspective on the existential relevance of work and on political action for its emancipation, with undeniable influences from Hegel, Marx and Bernstein.

Keywords: labor law, labor council, Weimar laboratory, work philosophy.

RÉSUMÉ: La voie choisie par le mouvement révolutionnaire et ses conseils ouvriers dans la République de Weimar a permis de faire progresser la législation du travail considérée comme un moyen efficace d'intégrer socialement les travailleurs dans les entreprises capitalistes soumises à de fortes tensions au début du XXème siècle. Un élément joua un grand rôle dans cette progression : le dénommé Laboratoire Weimar, où une poignée d'auteurs, indéniablement influencés par Hegel, Marx et Bernstein, mettront au point les formules juridiques et politiques qui seront à la base du développement de la Législation du travail et qui, comme nous le démontrerons dans notre texte, sont animées par une philosophie portant sur l'importance existentielle du travail et de l'action politique dans un but émancipateur.

Mots-clés: droit du travail, conseil du travail, laboratoire de Weimar, philosophie de travail.

SUMARIO: I. Introducción. II. Nacimiento y resistencia. III. La expansión y la derrota. IV. Los precursores de Weimary del derecho del trabajo. V. Bibliografía.

\section{INTRODUCCIÓN}

$\Psi$ 1 derecho del trabajo nacerá en la resistencia y crecerá en la impotencia: en ambos casos, del movimiento obrero.

Es obvio que el derecho del trabajo no nace en la República de Weimar a comienzos del siglo pasado. Normas reguladoras del trabajo asalariado existieron durante todo el siglo XIX — basta recordar las leyes fabriles de inicios de ese siglo que limitaban la jornada—. ${ }^{1}$ En ese sentido, no es difícil distinguir

1 En el principio de las normas laborales habrá un testigo calificado que relatará —con pasión- la tensión política que recorrerá su origen. Marx dedicará largas páginas en su 
distintos momentos relevantes en su evolución: las primeras normas laborales, el nacimiento y la expansión del derecho del trabajo. En el intersticio del segundo y el tercero de esos momentos anidará lo que se conocerá como el laboratorio Weimar. ${ }^{2}$

¿En qué sentido puede decirse que el derecho del trabajo nace de la resistencia y crece en la impotencia del movimiento obrero?

La respuesta nos conduce, como parece obvio, fuera del derecho y no parece mayormente controvertible. El proceso evolutivo de la regulación jurídica del trabajo perseguirá, como si de una silueta se tratará, a la evolución del trabajo mismo.

En ese sentido, el derecho del trabajo no es sino expresión de una tensión que lo trasciende: la tensión política que produce el trabajo que pretende regular. Dicha tensión — que ha recorrido el trabajo en las sociedades capitalistas desde sus inicios- puede ser mirada a través del prisma de un péndulo que se mueve por fuerzas en contraste y oposición.

Ese péndulo, en palabras de Polanyi

obra mayor - El capital - para narrar los conflictivos momentos del nacimiento de las primeras leyes fabriles, particularmente las que buscaban limitar "el movimiento arrollador, desenfrenado y violento como avalancha" para prolongar la jornada de trabajo: “ $\mathrm{Nada}$ caracteriza mejor el espíritu del capital que la historia de la legislación fabril inglesa de 1833 hasta 1864!"; Marx, K., El capital, Santiago, Lom, 2010, p. 280. El mismo Marx, ahora en referencia a la ley de 10 horas de 1848, sostendrá categóricamente que "la lucha en torno de la limitación legal del tiempo de trabajo se enconaba tanto más, cuanto que — prescindiendo de la codicia amedrentada - tocaba en efecto la gran cuestión en disputa entre el ciego predominio de las leyes de la oferta y la demanda, que constituye la economía política de las clases medias [burguesía] y el control social de la producción mediante la inteligencia y la previsión sociales, que constituye la economía política de la clase obrera. De aquí que el Bill de las 10 horas no fuera meramente una gran conquista práctica; fue la victoria de un principio. Por vez primera sucumbió a plena luz del día la economía política de la clase media ante la economía política de la clase obrera". Citado en Domènech, A., El eclipse de la fraternidad, Madrid, Akal, 2019, p. 155.

2 La expresión proviene de la doctrina italiana, popularizada con la publicación del texto del mismo nombre. Varios autores, Laboratorio Weimar, Arrigo y Vardaro (eds.), Roma, Lavoro, 1982. Alude al puñado de autores que confluirán en el tiempo histórico de la Alemania del veinte del siglo pasado - la llamada República de Weimar- que con sus reflexiones pusieron las bases del desarrollo del derecho del trabajo para el siglo veinte, tanto para Europa como, desde ahí, para el resto de la tradición jurídica occidental. Algunos irán más allá del laboralismo, como Fraenkel o Neumann, que terminarán siendo autores relevantes en la ciencia política comparada, o Korsch que se erigirá — junto a Lukács o Gramsci- como uno de los máximos filósofos del marxismo del siglo pasado. Otros, como Sinzheimer, será llamado el padre del derecho del trabajo europeo. Véase La lucha por el nuevo derecho del trabajo, Valparaíso, Edeval, 2017. 
...puede personificarse como la acción de dos principios de organización de la sociedad, cada uno de los cuales establece objetivos institucionales específicos, contando con el apoyo de fuerzas sociales definidas y usando sus propios métodos distintivos. Uno era el principio del liberalismo económico que buscaba el establecimiento de un mercado autorregulado, contaba con el apoyo de las clases comerciales, y usaba como métodos el laissez-faire y en gran medida al libre comercio; el otro era el principio de protección social que buscaba la conservación del hombre y la naturaleza, así como de la organización productiva, que contaba con el apoyo variable de la mayoría de quienes se veían inmediatamente afectados por la acción nociva del mercado, sobre todo de la clase trabajadora [y que recurre] a los métodos de la legislación protectora. ${ }^{3}$

Tensión irresoluble provocada por el proceso de transformar en trabajo abstracto (cantidad de fuerza de trabajo comprada por el empresario capitalista expresada en unidades de tiempo) el trabajo vivo (potencia productiva y cooperativa emanada de la fuerza de trabajo), sobre la que se proyectan dos fuerzas sociales antagónicas: las que presionan hacia la total mercantilización de la sociedad, y las que la resisten para proteger dimensiones vitales de la misma.

El trabajo queda enmarcado dentro del movimiento pendular que explica el desarrollo político dentro de las sociedades capitalistas, y junto con él, el derecho que lo regula.

¿Qué significa para el sistema legal el péndulo de Polanyi en la regulación jurídica del trabajo?

La oscilación pendular quedará determinada, hasta el día de hoy, por la confrontación de dos fuerzas que se oponen y resisten mutuamente: la de la mercantilización y la de la protección del trabajo. Como explica Silver,

...cuando el péndulo oscila hacia la mercantilización de la fuerza de trabajo, provoca fuertes contratendencias que exigen protección. Así, la globalización de finales del siglo XIX y principios del siglo XX provocó un fuerte contramovimiento de los trabajadores y otros grupos sociales. Como respuesta a la creciente militancia obrera, y a raíz de las dos guerras mundiales y la depresión, tras la segunda guerra mundial el péndulo osciló a la desmercantilización del trabajo. ${ }^{4}$

3 Polanyi, K., La gran transformación, México, Fondo de Cultura Económica, 2001, p. 187.

4 Silver, B., Fuerzas del trabajo: los movimientos obreros y la globalización desde 1870, Madrid, Akal, 2005, p. 31. 
Así, cada una de dichas fuerzas sociales del trabajo en tensión exigirá una mediación diferente por parte del derecho, en términos de la dirección política de la intervención jurídica del proceso de intercambio de trabajo por salario. De ahí que como lo apunta lúcidamente Hepple, "el elemento crucial en la elaboración del derecho del trabajo es el poder", y que "la legislación laboral se considera el resultado de un proceso de lucha entre diferentes grupos sociales". 5

Por supuesto, el sentido y dirección de esa mediación de lo jurídico estará determinado por el equilibrio de dichas fuerzas en conflicto en el momento regulatorio de que se trate, en el marco, en cualquier caso, de la pervivencia y consolidación del modelo de sociedad capitalista. ${ }^{6}$

Veamos los hitos centrales de la oscilación del péndulo para el derecho del trabajo.

\section{NACIMIENTO Y RESISTENCIA}

Durante el siglo diecinueve, la necesidad de transformación del trabajo en una mercancía abundante y barata, condición básica para la expansión

5 Hepple, B., "Introducción", en varios autores, La formación del derecho del trabajo en Europa, Madrid, Ministerio del Trabajo y Seguridad Social, 1994, p. 21.

6 Como ha explicado Poulantzas, más que ver en el derecho — como forma de regulación estatal — una simple expresión refleja de la dominación e intereses de clase dominante en el espacio de la economía o modo de producción, el Estado "posee siempre una autonomía relativa con respecto de tal o cual fracción del bloque en el poder", constituyéndose "como una relación, más exactamente como la condensación material de una relación de fuerzas entre clases y fracciones de clases". Poulantzas, N., Estado, poder y socialismo, México, Siglo XXI, 2014, p. 153. En ese sentido, el derecho del trabajo como construcción política-jurídica del siglo XX, tiene la cancha rayada por el sistema producto-capitalista: su regulación se podrá mover dentro del espacio o campo ya determinado por las exigencias de la producción, esto es, de la valorización por medio del trabajo abstracto y su plusvalía. Dentro de ese espacio, se generará una planicie antagonista que enfrentará a las fuerzas productivas y que, dependiendo de la capacidad y el poder político de ellas, podrá devenir en sistemas legales con fuerte intervención legal en protección de los trabajadores o/y en sistemas con fuerte capacidad de acción colectiva de los propios trabajadores. Pero cualquiera que sea el tipo de derecho del trabajo de que se trate, su finalidad nunca alcanza la impugnación de la totalidad sistémica capitalista. Las categorías estructurantes del orden capitalista le son trascendentes, porque su función central, de hecho, es dar curso jurídico a las exigencias de ese orden: que el trabajo abstracto sea una mercancía que se intercambia para la producción de plusvalía. En rigor, cuestionar la estructura capitalista del trabajo habría supuesto poner "en tela de juicio el valor de cambio", esto es, poner "en tela de juicio la producción de una cantidad medible de valor, y por tanto, conmensurable de trabajo abstracto, cuya finalidad principal es el crecimiento y la acumulación y no el uso social de la riqueza". Chicchi, F. et al., Más allá del salario, Madrid, Enclave, 2018, p. 33. 
territorial del capitalismo, supuso una exigencia de mediación específica para el derecho: el establecimiento de normas que permitieran la venta de la mercancía "trabajo". Dicha mediación determinada por la exigencia del sistema productivo supondrá una regulación jurídica que garantice la libertad de trabajo de los portadores de dicha mercancía.

En ese sentido, "el contrato era el único mecanismo jurídico que podía plasmar la libertad e igualdad formal de las partes y al mismo tiempo hacer posible que la burguesía planificara y orientara el proceso de acumulación del capital", y la forma contractual elegida será — mayoritariamente- el contrato de arrendamiento:

...la definición de la relación laboral como locatio conductio operarum en los países de Civil Law implicó la despersonalización de la relación, dado que el objeto del contrato no era la persona sino la fuerza de trabajo del obrero que ponía su trabajo en el mercado, como hacía cualquier propietario de un bien cualquiera, con un precio variable según su valor de cambio. ${ }^{7}$

En esa sociedad capitalista no era necesaria la protección del trabajador, ni menos la existencia del contrato de trabajo. Y no lo era, porque los contratos existentes aseguraban la satisfacción de las exigencias del sistema productivo, que era la libre circulación de la mercancía trabajo. No obstante, dicha situación no perduraría en el tiempo.

En efecto, esta mediación entre capital y trabajo, ahora vestidos constitucionalmente como "propietario" y "trabajador", estará constituida por una tensión irresoluble. Tensión que viene explicada por la naturaleza artificial de la mercancía sobre la que versa. La artificialidad del trabajo puede ser mirada del siguiente modo: por una parte, es una mercancía que no puede ser desarraigada de su productor. Por otra, su productor — y por tanto, la propia mercancía - está dotado de una pretensión moral y política ineludible: la resistencia fundada en la dignidad.

De modo tal que, junto con la forma organizativa que impone el rendimiento del capitalismo, se produce el fortalecimiento de su propia resistencia: "la resistencia contra la valorización en el proceso laboral se ve también incrementada por la conciencia política que produce la cooperación". ${ }^{8} \mathrm{Y}$ es que, como sugiere Read:

\footnotetext{
7 Veneziani, B., "La evolución del contrato de trabajo", en varios autores, La formación del derecho..., cit., p. 81 .

8 Negri, T., Marx y Foucault, Buenos Aires, Cactus, 2019, p. 45
} 
...aunque la producción de trabajo abstracto implica la transición desde la cualidad — los diversos cuerpos puestos a trabajar — a la cantidad — la hora calculable de tiempo de trabajo-, no es reducible a esta transición dialéctica. El trabajo no es un inerte colector de cualidades que es homogenizado y cuantificado; por el contrario, es una multitud de cuerpos que resisten a través de su irreducible pluralidad y heterogeneidad. Por ello, la transición de la cualidad a la cantidad abre otro problema: el problema político del control del trabajo vivo. ${ }^{9}$

Esa fuerza de resistencia a la mercantilización del trabajo se expresará en un actor que progresivamente se robustece en poder e influencia, como el proletariado. La creciente relevancia del movimiento obrero, incluida su progresiva incorporación al cuerpo electoral de las democracias occidentales, supondrá la dictación progresiva de normas laborales que limiten los aspectos más brutales de la explotación laboral, especialmente relevante serán las referidas a las normas de limitación de jornada de trabajo. En ese sentido, la resistencia colectiva a la explotación extensiva estará en el origen del nacimiento de normas estatales de protección, las que limitarán la explotación del trabajo humano disponible.

Pese a ello, en el corto plazo, dichas normas protectoras, nacidas de la resistencia obrera, convivirán buena parte del siglo XIX con la contratación civil como medio jurídico de la relación trabajo-capital. ${ }^{10}$ Se trata de una situación extraña: la existencia de normas protectoras de los trabajadores vinculados a sus empleadores por vínculos contractuales civiles. ${ }^{11}$

9 Read, J., La micropolítica del capital, Madrid, Tierra de Nadie Ediciones, 2016, p. 134.

10 Normas civiles o comerciales y eventualmente penales, serán suficientes para garantizar lo exigido por la empresa capitalista al sistema jurídico de ese momento histórico: la fijación del portador de la fuerza de trabajo, por un tiempo ilimitado, en el espacio arquitectónicamente cerrado que es la fábrica. Para ello, como explica Hepple, en los Estados liberales se mantenía el "orden interno de las fábricas" a través "del sistema del work-book (cartilla de trabajo) en la Europa continental, y por medio de sanciones penales para los trabajadores absentistas en Gran Bretaña, hasta el último cuarto del siglo XIX”. Hepple, B., op. cit., p. 37. En ese sentido, la dominación del capital se impuso a través de la instrumentalización del poder absoluto del empresario en la fábrica, tal como se refleja en los reglamentos de trabajo en la empresa y en el sistema de multas y otras sanciones que constituyeron el derecho penal de los talleres. Id., op. cit., p. 47.

11 La razón de esta extraña situación histórica es el tipo de mediación jurídica que realiza lo que llamamos derecho del trabajo. El derecho del trabajo es una forma de mediación de segundo grado, esto es, una mediación que se construye sobre otra intervención previa: la constitucional de la libertad de trabajo. La mediación básica — de primer orden— exigida por el sistema productivo al derecho es la constitución del trabajo como mercancía —-más modernamente 
Esa resistencia y sus éxitos tendrá, sin embargo —en el largo plazo-, un efecto paradójico. Provocará la necesidad creciente y urgente para la empresa capitalista de intensificar el ritmo de trabajo, en una jornada ahora limitada y continua. Se producirá, entonces, un sorpresivo efecto tecnológico: la aceleración de la introducción de la máquina en el lugar de trabajo, como forma de compensación de la reducción en la extensión de la jornada.

Como explicará Read:

...en la lucha en torno a la jornada laboral en Inglaterra, hay una especie de victoria: la jornada laboral se acorta y, lo que es más, la clase obrera es reconocida como fuerza política e institucionalizada en el derecho. Esta lucha pone fin a una forma de explotación, aquella fundada sobre la extensión de la jornada laboral, y hace surgir otra forma: una explotación intensiva, asentada sobre la imposición de un trabajo más productivo.

Por lo cual sucede "una inversión masiva en la transformación tecnológica del proceso de trabajo". ${ }^{12}$ En el mismo sentido, "en la propia historia del desarrollo capitalista, la lucha por la jornada laboral normal precede, impone, provoca un cambio en la forma del plusvalor, una revolución en el modo de producción". ${ }^{13}$

Esa revolución del uso intensivo de la fuerza de trabajo provocará la incorporación progresiva de tecnología — la máquina de vapor y la cadena de

la articulación de lo que llamaríamos un mercado de trabajo- Esa mediación es realizada por fuera de la órbita del derecho del trabajo, específicamente a través de las normas constitucionales que ratifican, por el lado del capital la propiedad privada, y por el lado del trabajo la libertad de trabajo. Ambos vectores subjetivos — propietario y trabajador- confluyen en una mercancía que es el trabajo. La mediación del derecho del trabajo — de segundo orden— opera sobre la base constituida por el régimen constitucional de la sociedad capitalista, con sujetos ya constituidos como propietario y como oferente de trabajo. Esa mediación surge tensionada por su ambivalencia, cuestión explicada por la naturaleza de la mercancía que regula.

12 Read, J., op. cit., p. 136.

13 Tronti, M., Obreros y Capital, Madrid, Akal, 2001, p. 217. En el largo plazo esa transformación tecnológica dará lugar, en palabras de Gramsci, a "una revolución pasiva — provocada por la clase dominante y sufrida por la clase dominada - que se conocerá como el taylorismo y que establecerá —más allá de izquierdas y derechas — una auténtica hegemonía para todo el siglo veinte sobre la organización del lugar de trabajo: "comprender la importancia, la significación y el alcance objetivo del fenómeno norteamericano, que es, entre otras cosas, el mayor esfuerzo colectivo realizado hasta ahora por crear, con rapidez y con una consciencia de los fines jamás vista en la historia, un nuevo tipo de trabajador y de hombre", y que no es otro, en frase de Taylor, que el "gorila amaestrado". Gramsci, A., Antología, México, Siglo XXI, 2010, p. 476. 
montaje-, y la creación de una cultura organizativa complementaria — la organización científica del trabajo (taylorismo)—. Dicha combinación se traduciría en la urgente necesidad de someter disciplinaria y técnicamente a la fuerza de trabajo, y ya no sólo localizándola geográficamente dentro de la fábrica. Esa exigencia implicaría, en los términos de Marx, un nuevo proceso: la subsunción real del trabajador. ${ }^{14}$

Ese acentuado nivel de sometimiento tecnológico-disciplinar del trabajador a la exigencia productiva de la empresa en el capitalismo industrial, requerirá de una nueva forma jurídica que dé vestimenta legal al proceso en curso, nacerá el contrato de trabajo y su idea nuclear de la subordinación. En efecto, mirado desde la regulación jurídica, la exigencia técnica descrita supuso una torsión: el derecho se vio forzado a diseñar una estructura jurídica de la que no disponía.

De ahí que se afirme que

...el concepto de subordinación se transformó a raíz de la expansión de la industria a gran escala. La característica típica del contrato de trabajo en la fábrica no consistía ya en el tipo de remuneración por el que el trabajador acordaba intercambiar sus servicios (proporcionalmente a las horas trabajadas, si el trabajo era del tipo de los regidos por el tiempo, o proporcional a los resultados, si era un trabajo a destajo). El criterio esencial era la dependencia y el control. ${ }^{15}$

En pocas palabras, el capital requerirá el sometimiento disciplinario y técnico del trabajador, y el derecho se lo otorgará en la forma jurídica de sub-

14 El capitalismo inicial sometía el trabajo en aquello que Marx denominó la "subsunción formal: las exigencias del capital eran garantizar el sometimiento físico del trabajo - la fuerza del trabajo- - en cuanto, el conocimiento y el saber productivo seguía radicado en el trabajador. En sus palabras "sobre la base de un modo de trabajo preexistente, o sea de un desarrollo dado de la fuerza productiva del trabajo y de la modalidad laboral correspondiente a esa fuerza productiva, sólo se puede producir plusvalía recurriendo a la prolongación del tiempo de trabajo, es decir, bajo la forma de plusvalía absoluta. A esta modalidad, como forma única de producir plusvalía, corresponde pues la subsunción formal del trabajo en el capital"; Marx, El capital, cit., p. 56. En la subsunción real, en cambio, "se efectúa una revolución total (que se prosigue y repite continuamente en el modo de producción mismo, en la productividad del trabajo y en la relación entre el capitalista Y el obrero" y "se desarrollan las fuerzas productivas del trabajo y merced al trabajo en gran escala, se llega a la aplicación de la ciencia y la maquinaria a la producción mediata"; Marx, K., El capital, Libro I, capítulo VI (inédito), México, Siglo XXI, 2015, p. 72.

15 Veneziani, B., op. cit., p. 90 
ordinación. Dicha subordinación será, en ese sentido, "un instrumento que sirve sin duda para limitar, pero también para dar fundamento jurídico y reconocer la legitimidad del ejercicio de un poder necesario para predisponer la organización del trabajo". ${ }^{16}$

De la necesidad de garantizar el control y la disciplina del trabajador nace la subordinación, y de pasada, surge el entramado normativo que le dará sentido: el derecho del trabajo.

\section{LA EXPANSIÓN Y LA DERROTA}

Después de nacer, vendría la expansión. Pero antes, como dijimos, se requiere una derrota. En efecto, el derecho del trabajo se va a expandir sobre una loza, la de la tumba política de la revolución proletaria. Grabada en esa loza, con letras doradas, los nombres, entre otros, de Luxemburgo, ${ }^{17}$ Gramsci, ${ }^{18}$ Korsch y Pannekoek. ${ }^{19}$

16 Loffredo, A., "La identificación entre contrato y trabajo en los orígenes y en la actualidad del derecho italiano", Revista Derecho Social, Alicante, Bomarzo, núm. 68, 2014, p. 49.

17 Luxemburgo será una de las figuras centrales del Partido Comunista alemán (KDP), que, apenas fundado en 1919, emitirá un manifiesto llamando a disolver "la Asamblea Nacional de la burguesía y de sus lacayos social-patriotas" y entregar "todo el poder a los consejos obreros y soldados revolucionarios". Luxemburgo, R., La Comuna de Berlin, México, Grijalbo, 1971, p. 101.

18 Gramsci publicará — junto con Togliatti- el 21 de junio de 1919 en el semanario L'Ordine Nuovo un influyente artículo titulado "Democracia obrera", donde expresaran que "las comisiones internas son órganos de democracia obrera, que hay que liberar de las limitaciones impuestas por los empresarios", ya que sólo "hoy limitan el poder del capitalista en la fábrica y cumplen funciones de arbitraje y disciplina. Desarrolladas y enriquecidas, tendrán que ser mañana los órganos del poder proletario que sustituirá al capitalista en todas sus funciones útiles de dirección y de administración". Gramsci rematará — parafraseando a Lenin— "todo el poder de la fábrica a los comités de fábrica, coordinada con esta otra: todo el poder del Estado a los consejos obreros y campesino". Gramsci, A., Antología, México, Siglo XXI, 2010, p. 60. Este texto se consideraría fundamental en la influencia en el denominado bienio rojo italiano (1919-1920), que se caracterizó por la toma de las fábricas por parte de los trabajadores, que como dirá Wallis, "era el primer caso de una dinámica de ocupación de fábricas en una democracia capitalista e inspiró una estrategia novedosa en donde la revolución obrera no se forzaría a través de la parálisis de la producción (huelga general) sino más bien a través de alcanzar su control”. Wallis, V., "Control obrero y revolución”, en varios autores, Poder obrero, Madrid, La Oveja Roja, 2017, p. 34.

19 Pannekoek — considerado el teórico de la izquierda consejista- lideró una tendencia conocida como "tribunistas" — debido al periódico Tribune que publicaban—, la cual enfrentará al movimiento socialdemócrata holandés — posteriormente convertido en el Partido Co- 
Ellos creían, en su momento, en la revolución proletaria de la mano del movimiento obrero. Y aunque pudieran diferir del medio de lograrlo — entre la revolución política o la huelga de masas-, lo relevante es que situaron políticamente el horizonte de la emancipación de los trabajadores en el mismo punto: la organización y control de la producción a través de los consejos o comités obreros. ${ }^{20}$ Como se dirá, el movimiento obrero durante la revolución alemana de 1918 no sólo "derrocó la monarquía en Alemania y puso fin a una Gran Guerra que ya había costado millones de vidas", también "inspiró una idea completamente nueva de socialismo que se centró no en el poder estatal y la centralización sino en la democracia de base y el control obrero: la idea del comunismo consejista". ${ }^{21}$

munista-, en razón de su radical diferencia en torno al rol de los propios trabajadores en la construcción de la sociedad comunista. Para Pannekoek, los consejos obreros son una forma superior de formación política a la democracia parlamentaria: "en los consejos, los obreros están representados en sus grupos de origen, en la fábrica, en el taller o en el complejo industrial en el que trabajan. Los obreros de una fábrica constituyen una unidad de producción; forman un todo por su trabajo colectivo. En un período revolucionario se hallan, pues, inmediatamente en contacto para intercambiar sus puntos de vista: viven en las mismas condiciones y tienen intereses comunes. Deben actuar de acuerdo y son ellos quienes deben decidir si la fábrica, en tanto que unidad de producción, ha de ir a la huelga o seguir funcionando. Para ello la única forma posible es la organización y la delegación de los trabajadores en las fábricas y talleres. Los consejos son al mismo tiempo la garantía del impulso del comunismo en el proceso revolucionario. La sociedad está fundada en la producción, o, dicho más correctamente, la producción es la esencia misma de la sociedad, y, por consiguiente, la marcha de la producción determina la marcha de la sociedad". Pannekoek, A., Crítica del bolchevismo, Barcelona, Anagrama, 1976, p. 90.

20 Todo comenzó, según apunta Weitz, en la ciudad alemana de Kiel —el 29 de octubre de 1918 - donde los marinos se amotinaron en protesta por la orden de sus almirantes de hacerse a la mar para acciones bélicas, y "aquella actitud [cuenta Weitz] prendió la mecha de la revolución que acabaría con la Alemania imperial. La revuelta de los marineros no tardó en ser imitada en los cuarteles de tierra y, más tarde, por los trabajadores de cada ciudad”; lo más sorpresivo es que los marinos fueron "los instauradores de un órgano que, con el tiempo, llegaría a ser una de las instituciones democráticas de la revolución: el comité. Los comités habían aparecido durante las revoluciones rusas de 1905 y 1917 como órganos de expresión popular", siendo para "sus partidarios, de extracción obrera, sobre todo, los comités, especialmente en los momentos álgidos de la revolución, como el invierno de 1918-1919 o la primavera de 1920, eran la vía definitiva para llevar la democracia y el socialismo a Alemania". Weitz, E., La Alemania de Weimar. Presagio y tragedia, Madrid, Turner, 2009, p. 30.

21 Hoffrogge, R., "Del sindicalismo a los consejos obreros", en varios autores, Poder obrero: control y autogestión obrera, Madrid, La Oveja Roja, 2017, p. 126. Lo de la novedad del consejismo en la revolución alemana es controvertible: como señala Arendt "las fechas principales de aparición de estos órgano de acción son las siguientes: 1870, cuando la capital francesa asediada por el ejército prusiano, se reorganizó espontáneamente en un cuerpo federal en miniatura, 
Una idea — la del sistema consejista— que recorrerá la historia política de las sociedades desde la aparición del proletariado, y que será vista mucho más allá de la versión fabril-productiva, expresando, en palabras de Arendt, un espacio de libertad "que bajo las condiciones contemporáneas, los consejos son la única alternativa democrática que conocemos al sistema de partidos, y los principios en que descansa están en muchos aspectos en aguda oposición a los del sistema de partidos", y cuyo sentido es "una forma nueva de gobierno que permitiría a cada miembro de la sociedad igualitaria moderna llegar a ser partícipe en los asuntos públicos". ${ }^{22}$

La idea del consejo obrero, por otra parte, representó una genuina sorpresa para la forma en que el pensamiento socialista imaginaba la forma política del futuro:

...este modelo de organización desde la base tomó por sorpresa a todos los grandes teóricos del socialismo. Ya fueran centristas como Kautsky o radicales de izquierda como Lenin o Rosa Luxemburgo, durante décadas todos ellos habían imaginado el socialismo el punto final de la progresiva centralización del poder económico y el poder estatal. Ahora, en medio de una de las mayores crisis que el capitalismo había visto, los trabajadores generaron por sí mismos un modelo de socialismo que no se construía sobre la idea de la planificación económica centralizada, sino que se focalizaba en el autogobierno de la clase obrera. ${ }^{23}$

que formó después el núcleo de la Comuna de París en la primavera de 1871; 1905, cuando la oleada de huelgas espontáneas a través de Rusia determinó la formación espontánea de la dirección política al margen de todos los grupos y partidos revolucionarios, y los obreros de las fábricas se organizaron en consejos, sóviets, con el propósito de instituir un gobierno autónomo representativo", y en fin "la Revolución de febrero de 1917 en Rusia, cuando a pesar de existir diferentes tendencias políticas entre los trabajadores rusos, la organización, es decir, el sóviet, no se discutió”. Arendt, H., Sobre la revolución, Madrid, Alianza Editorial, 2017, p. 433.

22 Arendt, H., op. cit., p. 438.

23 Hoffrogge, R., op. cit., p. 126. La potente influencia del ideal consejista se expandirá por buena parte del mundo, incluyendo América Latina. Así, por ejemplo, el influyente fundador del socialismo chileno - el tipógrafo Emilio Recabarren— erigirá en la década del veinte una propuesta de organización política con innegables raíces consejistas: la sustitución de la propiedad privada por la propiedad social: "la administración de esta propiedad y la distribución de sus frutos sería entregada a 'asambleas industriales' de base, las que a su vez enviarían delegados a un poder municipal que reglaría todos "los asuntos generales que interesen al bienestar de los habitantes de su respectivo territorio". A su vez, el conjunto de municipalidades daría origen a una "Asamblea Nacional que asumiría la conducción central del país" configurándose así "una República Federal Socialista de Chile". Pinto, J., Luis Emilio Recabarren: una biografía histórica, Santiago, Lom, 2013, p. 192. 
Pero la revolución proletaria —el fantasma que recorría Europa - fracasará en Occidente, y la parte del movimiento obrero que la sustentaba será impotente para llevarla adelante con éxito, ${ }^{24}$ ya que "en todas partes el capital demostró ser más fuerte". ${ }^{25}$

Como se dirá:

...a pesar de su fortaleza y empuje, este movimiento fue de muy corta duración. A finales de 1920 la clase obrera estaba representada exclusivamente por partidos políticos y sindicatos. ¿Qué pasó? La revolución y sus consejos se vieron frenados tanto por la violencia contrarrevolucionaria como por su incapacidad de desarmar a las élites económicas y políticas de la Alemania imperial. ${ }^{26}$

La revolución socialista, resumirá Hobsbawm, "nunca viajó desde Petrogrado hasta Berlín". ${ }^{27}$

La derrota revolucionaria deberá ser, entonces, sublimada. ${ }^{28}$ Las fuerzas políticas asociadas el movimiento obrero trasladarán su fuerza libidinal de la

24 No será, por supuesto, una situación excepcional, especialmente referida a la historia del movimiento obrero-sindical. Como explica Anderson, "el potencial del poder que tienen los sindicatos es sólo sectorial, no universal. En una sociedad capitalista no hay paridad de poder entre la 'administración' y el 'trabajo', porque el trabajo es un elemento no transformable que sólo puede ser retirado (o, a lo sumo, utilizado para la ocupación, por ejemplo), el capital es dinero, un poder universalmente transformable que se puede 'hacer efectivo' en formas diferentes" esto se comprueba "en cualquier examen que tengamos de la experiencia histórica de la acción sindical que rebase los límites de la negociación salarial. Resulta curioso que un movimiento sindical, tiende a tropezar con las mismas limitaciones estructurales en su acción, ya sea que adopte una postura revolucionaria o reformista. Estas limitaciones han condenado a un mismo fracaso a las tentativas inspiradas en los propósitos más diversos". Anderson, P., "Las limitaciones y las posibilidades de la acción sindical”, Pensamiento Crítico, Habana, núm. 13, 1968, p. 119.

25 Anderson explicará que "la represión de la insurrección del mes de enero en Berlín pronto fue seguida por la reconquista militar de Múnich por la Reichswehr, donde grupos socialistas y comunistas locales habían creado en abril una efímera República Soviética Bávara. La revolución alemana, nacida de los consejos obreros y soldados formados en noviembre de 1918, fue definitivamente derrotada en 1920". Anderson, P., Consideraciones sobre el marxismo occidental, Madrid, Siglo XXI, 2017, p. 25.

26 Hoffrogge, R., op. cit., p. 127.

27 Hobsbawm, E., Cómo cambiar el mundo, Buenos Aires, Crítica, 2011, p. 412. Por el contrario, agregará el historiador inglés, "se restauró el antiguo régimen, sin emperador, pero con el elemento adicional de una socialdemocracia apasionada y visceralmente antirrevolucionaria y gubernamental". Hobsbawm, E., Revolucionarios, Madrid, Crítica, 2010, p. 70.

28 Esa impotencia será para cierta teoría crítica, en principio, política. Con el tiempo, devendrá en existencial u ontológica. Lukács publicará en 1923 un conocido ensayo —bajo el nombre de "Historia y conciencia de clase" de 1923 - en donde atribuye a la subjetividad 
revolución a la reforma, de la superación del capitalismo a la protección contra la explotación. ${ }^{29}$ Se mantendrá, en cualquier caso, una narrativa portante de la simbología política emancipadora, pero acompañada, en simultáneo, de una práctica más modesta, y esencialmente circunscrita a la mejora de las condiciones de trabajo y salariales. ${ }^{30}$

Esa sublimación se hará operativa, en palabras de Hobsbawm, en una "simbiosis reformista" entre movimiento obrero-sindical y economía capitalista, que se extenderá por buena parte del siglo veinte: "tras la segunda

cosificada de los trabajadores, un efecto propio del capitalismo, el bloqueo a la acción revolucionaria. Pocos años después -1926 - Horkheimer dará una explicación eminentemente política al fracaso, la que cifrará en la lógica productiva del capitalismo. Dicha lógica produce un efecto no previsto. El sistema productivo divide los trabajadores en dos: los integrados con salario y protección sindical, y los excluidos — fundamentalmente los desempleados-; fragmentación que se expresara en las mismas fuerzas políticas que los representaran —en la Alemania de Weimar-: los socialdemócratas y los comunistas. Entre estas categorías de trabajadores se crea un abismo que inhibe significativamente la capacidad revolucionaria del proletariado. Horkheimer, Max, "La impotencia de la clase obrera alemana", Ocaso, Madrid, Taurus, 1986, pp. 85-91.

29 La principal de esas fuerzas políticas en el caso alemán —el Partido socialdemócrata (SPD) - tenía desde principios de siglo veinte dos tendencias diferentes: "una de carácter revolucionario, que impulsaba sus acciones hacia la liquidación de régimen imperial y el sistema capitalista, y tenía como horizonte político, económico y social la implementación de una república socialista. Y otra, centrorreformista, que consideraba la transformación del régimen una cuestión secundaria por cuanto era posible integrar ambas opciones, socialista y monárquica, en un espacio político neutro, y después realizar las conquistas necesarias dentro del sistema establecido". Vicente, C. de, La revolución de 1918-1919. Alemania y el socialismo radical, Madrid, Catarata, 2018, p. 41.

30 La importación de terminología política al espacio de la producción será una constante histórica de la socialdemocracia y del movimiento obrero que la sustentaba, especialmente útil, según dijimos, como forma de sublimar la impotencia revolucionaria. Desde los Webbs, quienes utilizarán la expresión "democracia industrial" para uno de sus textos fundamentales - en rigor, un estudio de la cuestión sindical en Inglaterra a fines del siglo XIX-, la imaginación del mundo obrero y sindical no ahorra recursos políticos: democracia social, ciudadanía industrial, derechos de participación, etc. En el caso de los esposos ingleses, la idea de democracia industrial no tiene relación alguna con una pretensión de gestión obrera de la producción que cuestione los rasgos básicos de la empresa capitalista, sino una cosa bastante más modesta: la participación sindical en la determinación de los salarios y las condiciones de trabajo. Así afirmarán categóricamente que, en su democracia industrial, "cualquiera sea la forma en la que se resuelva esta cuestión, una cosa es segura: que las distintas secciones de trabajadores manuales afiliados en sus sindicatos no tendrán, ni en la empresa privada ni en el colectivismo, más que ver con la determinación de lo que debe producirse más que los demás ciudadanos o consumidores". Webb, S. y Webb, B., La democracia industrial, Madrid, Fundación Largo Caballero, 2004, p. 607. 
guerra mundial, la simbiosis se buscó de forma más sistemática como parte de una política de reforma estructural del capitalismo occidental a través de la política deliberada de pleno empleo y de lo que se convirtió en el estado de bienestar". 31

Como expresará en términos paradójicos Tronti, "la victoria de la socialdemocracia constituye una derrota de la clase obrera, nadie lo puede negar". ${ }^{32}$ En efecto, la derrota del movimiento obrero revolucionario tendrá un efecto expansivo para el derecho del trabajo por dos razones: primero, dará fuerza a las prácticas laborales reformistas, especialmente las sindicales, y segundo, potenciará la perspectiva teórica del socialismo estatal dentro del pensamiento jurídico, cuyo eje central será la regulación legal y/o colectiva de los derechos de los trabajadores. ${ }^{33}$

Lo primero, lo harán los sindicatos — mediante la acción de pactar convenios colectivos que mejorarán la posición efectiva de los trabajadores—; 34 lo

31 Hobsbawm, E., op. cit., p. 413.

32 Tronti, M., Obreros y capital, Madrid, Akal, 2001, p. 26.

33 En el caso de América Latina, el pensamiento reformista-socialdemócrata se abrirá paso en medio de una fuerte tradición jurídica autoritaria y conservadora —expresada en el lema de "orden y progreso" en palabras de Gargarella-, apertura explicada por la idea de "presencia" en el espacio constitucional de grupos antes invisibles. Presencia derivada de cambios significativos en la región "en cuanto a su composición social. Ellos están dados, algunos casos, por la llegada de inmigrantes (pobres) europeos; en otros, crecimiento de la clase trabajadora (sobre todo, el proletariado urbano en la Argentina, Chile y México); y por el crecimiento en número y protagonismo de las capas medias, que comienzan a presionar por una participación política, a la que los gobiernos del 'autoritarismo con progreso económico’ se resistían sistemáticamente”. Gargarella, R., La sala de máquinas de la Constitución. Dos siglos de constitucionalismo en América Latina (1810-2010), Buenos Aires, Katz Editores, 2014, p. 174. En ese sentido, "la revolución política de México constituye la expresión más notable del descontento regional con el viejo sistema heredado, de 'orden y progreso"' $I d$., p. 187, lo que se expresará en una inédita Constitución de 1917 en términos de reconocimiento de derechos individuales y colectivos para los obreros.

34 Como se ha apuntado "lo que era más específico en el constitucionalismo social alemán, por lo tanto, venía a través del sindicalismo. Antes de ser constitucionalizado en 1919, el modelo se codificó en el llamado 'Pacto Legien-Stinnes', negociado entre octubre y noviembre de 1918. El acuerdo entre el jefe de la ADGB, Carl Legien, y el líder de los empleadores alemanes, Hugo Stinnes, sentó las bases de la "comunidad de trabajo", por la cual los sindicatos libres (socialistas) estaban comprometidos con una política de colaboración con el capital, cuyos representantes aceptaban ahora una reglamentación de sus relaciones en base a la representación paritaria. Además, este acuerdo permitía desactivar las visiones más radicales de la idea del consejo obrero en el momento de la Revolución de noviembre". Herrera, C. M., "El constitucionalismo social weimariano en el pensamiento francés entreguerras" Historia constitucional, Madrid, Centro de Estudios Políticos y Constitucionales, núm. 20, 2019, p. 467. 
segundo, los laboralistas de Weimar — posicionado los derechos de los trabajadores como el centro del socialismo reformista en Europa- ${ }^{35}$

Para decirlo de otro modo, el deseo de revolución será trocado por el deseo de protección. Y en ese sentido, un producto relevante de esa sublimación será, precisamente, el derecho del trabajo sinzheimeriano. ${ }^{36}$

\title{
IV. LOS PRECURSORES DE WEIMAR
}

Y DEL DERECHO DEL TRABAJO

\begin{abstract}
¿Qué hizo de Weimar un laboratorio tan relevante para el derecho del trabajo del siglo veinte?

El laboralismo weimariano hizo múltiples y seminales aportes a la construcción jurídica del derecho del trabajo, cuyo esplendor institucional sólo se expresaría concluida la noche fascista. Después de la Segunda Guerra Mundial las ideas políticas y jurídicas sembradas por ese exquisito laboratorio co-
\end{abstract}

35 Muestra notable de la influencia del laboralismo en Alemania de Weimar —y de ahí para toda Europa — será el rol de Sinzheimer en el contenido ideológico de la Constitución de 1919. El proyecto original presentado a la Asamblea Constituyente no incluía un catálogo de derechos fundamentales, Sinzheimer — como experto en el tema del Partido Socialdemócrata— presentó una propuesta para su inclusión con un marcado contenido sociolaboral: "si comparamos esta propuesta con el proyecto oficial por un lado y la versión final del texto constitucional por otro, no podemos dejar de advertir la importancia de este documento para la historia de la Constitución social de Weimar. Los puntos más decisivos con respecto al Estado social y a los derechos sociales ya estaban incluidos allí. En las sesiones posteriores sólo se efectuaron pequeñas modificaciones que no cambiarían en lo sustancial la propuesta elaborada por Sinzheimer. Su aporte como jurista fue fundamental para la redacción de estos artículos, porque si bien algunas de estas ideas eran compartidas por otros integrantes de la Asamblea él supo formularlas con forma jurídica y como se verá más adelante, también pudo fundamentarlas en un todo sistemático". Vita, L., "Constitucionalismo social como democracia económica. Una relectura de la Constitución de Weimar a la luz del aporte de Hugo Sinzheimer" Historia universal, Centro de Estudios Políticos y Constitucionales, núm. 19, 2018, p. 579.

36 Circunstancia histórica de la que, por lo demás, estarán muy claros sus miembros, como Fraenkel, y sus precisas palabras al respecto: "El derecho del trabajo adquirió un significado político sobre todo con el fin de las primeras ondas revolucionarias. La avanzada revolucionaria de la clase obrera no logró cambiar radicalmente la organización económica y social de entonces, pero sí estuvo en condiciones de reconducir y de anclar sólidamente en el campo de la política social y del derecho del trabajo los primeros intentos de transformación de la organización política y social que la revolución había logrado producir" de modo tal, que "cuando disminuyó el ímpetu revolucionario, el derecho del trabajo se volvió el recipiente en el que sedimentan las fuerzas revolucionarias antes de ser transformadas en nuevas formas jurídicas". Fraenkel, E., "Il significato politico del diritto del lavoro", en varios autores, Laboratorio Weimar, cit., p. 124. 
locarían al derecho del trabajo como núcleo central de la idea de Estado social de derecho, que sería el sello del constitucionalismo europeo de la segunda mitad del siglo veinte.

Sería, en todo caso, un error ver con los ojos de hoy en el laboratorio Weimar algo así como un espacio académico para el desarrollo exclusivo de las ciencias jurídicas del trabajo. Antes que todo, fue un espacio político-jurídico, de prueba y error, que entre fórmulas y reflexiones fuertemente ancladas al contexto histórico que le tocaba vivir, producía algunas fórmulas que, con el tiempo, sabríamos resistirían y se transformarían en las bases del derecho del trabajo, particularmente europeo, en la segunda mitad del siglo veinte.

Particularmente relevante, por razones obvias, es su aporte jurídico. En síntesis, en algo que afirmarán todos sus autores, la autonomía colectiva será el eje sobre que se construirá la perspectiva weimariana del derecho del trabajo. No sólo será el rasgo que le permitirá sostener la autonomía del derecho del trabajo frente al derecho civil —el altar de la voluntad individual del sujeto-, y además su prioridad valorativa frente a la perspectiva reglamentaria o legal de esa rama naciente del sistema jurídico. Una prioridad que se expresará en el rol subsidiario del poder estatal de reglamentación del trabajo en la relación salarial, dejando un amplio espacio de indeterminación para que los sujetos sociales lo doten de su propia regulación.

Como sugerirá el mismo Sinzheimer "el legislador no debe poner trabas a este desarrollo; al contrario, tiene que tornarlo fecundo. Su tarea es poner a disposición las necesarias formas jurídicas en que pueda realizarse voluntad de autodeterminación social". De hecho, explicará con rotundas palabras que "de esta suerte, las organizaciones sindicales adquieren en amplia medida la posibilidad de crear con autonomía su propio derecho del trabajo en campo del contrato, la judicatura, organización y administración laboral". ${ }^{37}$

Pero ¿que había detrás del pensamiento del laboratorio y sus reflexiones jurídicas?, ¿cómo explicar la concepción del trabajo que subyacía entre pluralidad de autores — no exentos de contradicciones y conflictos- que lo constituyeron?

Una buena forma puede ser mirar los hombros sobre los que estaban parados: sus antepasados, que eran en parte, hegelianos, en parte, marxistas y fundamentalmente — salvo Korsch— berstenianos.

37 Sinzheimer, H., "La reorganización del derecho del trabajo", La lucha por el nuevo..., cit., Edeval, Valparaíso,2017, p. 74. Para una revisión en detalle de las construcciones jurídicas del laboratorio Weimar, véase Gil, R., El derecho del trabajo democrático en la República de Weimar, Albacete, Bomarzo, 2017. 
La idea hegeliana — en palabras de Arendt— de la "glorificación del trabajo" 38 subyace en silencio en toda la labor de los autores que constituyen el laboratorio. Podrán discutirse todos y cualquier extremo del sentido de la regulación jurídica del trabajo, hasta incluso proponer — como Korsch- su extinción, pero ninguno discutirá ni por asomo la centralidad del objeto de regulación: el trabajo como expresión de la esencia de la humanidad. ${ }^{39}$

El trabajo permite, por una parte, que el ser humano se objetive en un mundo de cosas y artefactos que ha creado con sus manos y que son expresión de su humanidad, sometiendo y dominando la naturaleza. ${ }^{40}$ Como explica Marcuse,

...la acción del trabajador no desaparece al aparecer los productos de su trabajo, sino que se preserva en ellos. Las cosas que el trabajo configura y confecciona llenan el mundo social del hombre y funcionan allí como objetos del trabajo. El trabajador sabe que su trabajo perpetua el mundo; se ve y se reconoce a sí mismo en las cosas que lo rodean. ${ }^{41}$

\section{En ese sentido, como explica Fromm,}

...el trabajo es la autoexpresión del hombre, una expresión de sus facultades físicas y mentales individuales. En este proceso de actividad genuina, el

38 Arendt, H., Karl Marx y la tradición del pensamiento político occidental, Madrid, Encuentro, 2008, p. 18. Será en Marx, en todo caso, donde cristalizará en forma más perfecta, según Arendt, la glorificación del trabajo, ya que será el único pensador del siglo XIX que se "tomó en serio en términos filosóficos el acontecimiento central del siglo: la emancipación de la clase trabajadora". Marx captará, en ese sentido, como nadie "la importancia política de la emancipación de la labor, y la correspondiente dignificación de la labor como la más fundamental de todas las actividades humanas".

39 Como explica Meda, Hegel comandará “una revolución conceptual” en la idea del trabajo, "la que producirá sin alteraciones semánticas, lo que invita a pensar que el concepto no ha cambiado cuando, en realidad, su significado ha sido completamente transformado: el trabajo acabará presentándose como la esencia del hombre". Meda, D., El trabajo: un valor en extinción, Barcelona, Gedisa, 1998, p. 75.

40 Se trata de la llamada "concepción formativa" del trabajo: a través del él "modelamos al objeto, y le damos una forma humana. Nosotros así nos 'duplicamos' en el mundo. A través de este proceso establecemos una relación con el mundo natural, ya nuestros propios deseos naturales que están mediados por el trabajo. Nos objetivamos en nuestros productos y llegamos a reconocer nuestros poderes y habilidades, encarnados en el mundo. Nos desarrollamos como reflexivos. Seres autoconscientes". Sayers, S., "The Concept of Labor: Marx and his Critics", Science and Society, vol. 71, núm. 4, octubre de 2007, p. 441.

41 Marcuse, H., Rąón y revolución, Madrid, Alianza, 2015, p. 119. 
hombre se desarrolla, se vuelve él mismo; el trabajo no es sólo un medio para lograr un fin —el producto—- sino un fin en sí, la expresión significativa de la energía humana; por eso el trabajo es susceptible de ser gozado. ${ }^{42}$

Y al mismo tiempo, por otra, el trabajo transforma al trabajador, permitiendo que se encuentre a sí mismo: mediante el proceso de autoconciencia en su relación con otros. El trabajador (siervo) se transforma en conciencia "para sî" en su relación de trabajo con su empleador (amo). ${ }^{43}$ De este modo, la posición dominante está del lado del trabajador, es el trabajo la vía para el conocimiento de sí mismo, de volverse una "conciencia para sî":

...el siervo se ha decidido por la vida, retirado de la lucha entre la vida y la muerte, y sometido a la otra autoconciencia para la que ahora trabaja. En el trabajo se emancipa, adquiere mediante él la autosuficiencia efectivamente real de los objetos que serán trabajados y, de ese modo, de encontrar una distancia en relación con la vida. ${ }^{44}$

Esa centralidad hegeliana permeará al laboratorio Weimar de modo evidente, y se expresará en las categóricas palabras de Sinzheimer:

...el trabajo es una energía esencial. Quien presta trabajo no da ningún objeto patrimonial, sino que se da a sí mismo. El trabajo es el hombre mismo en situación de actuar. El hombre tiene una dignidad. Lograr tal dignidad es la misión especial del derecho del trabajo. Su función consiste en evitar que el hombre sea tratado igual que las cosas. ${ }^{45}$

Esa centralidad existencial devendrá —en las letras de los laboralistas de Weimar- centralidad jurídica:

42 Fromm, E., Marxy su concepto del hombre, México, Fondo de Cultura Económica, 2016, p. 52.

43 En palabras del mismo Hegel: "la verdad de la conciencia autosuficiente es, por tanto, la conciencia servil. Es cierto que ésta comienza apareciendo fuera de sí, y no como la verdad de la autoconciencia. Pero, así como la dominación revelaba que su esencia es lo inverso de aquello que quiere ser, así también la servidumbre devendrá también, sin duda, al consumarse plenamente lo contrario de lo que de un modo inmediato es; retornará a sí como conciencia repelida sobre sí misma y se convertirá en verdadera autosuficiencia” Hegel, G.W.F., Fenomenología del espiritu, México, Fondo de Cultura Económica, 2017, p. 99.

44 Bonsiepen, W., 'Introducción', en ibidem, p. XLV.

45 Sinzheimer, H., Crisis económica y derecho del trabajo. Cinco estudios sobre la problemática humana y conceptual del derecho del trabajo, Madrid, Ministerio del Trabajo y Seguridad Social, 1984, p. 73 
...del ser humano desnudo, de esa "persona", sombra volatilizada del hombre, debe llegarse a un ser protegido que no viva sólo en el ambiente etéreo del espíritu, sino de la plena existencia. El derecho del trabajo contribuye de manera decisiva a la constitución de semejante orden jurídico social, al colocar en el centro de su normativa no sólo la propiedad, sino la humanidad. El derecho del trabajo quiere llenar aquel vacío que existe entre el hombre y "la persona", implantar el orden social en medio del orden jurídico, dar a la nueva época social su derecho. ${ }^{46}$

Marxistas para correr el velo, siguiendo al mismo Marx, dentro del "laboratorio secreto de la producción”, y derribar un mito de la doctrina jurídica liberal: que la relación de trabajo no es más que un acuerdo entre particulares libres e iguales y poco más. Como destacaran sus autores — Sinzheimer, Fraenkel, Kahn-Freund o Korsch—-, detrás de la ficción del contrato, lo que hay es una relación de dominación y poder. Sumisión articulada sobre un soporte último que es la propiedad privada.

Las claves marxistas del laboratorio Weimar están por todos lados, pero pueden condensarse en dos ideas fundamentales: el trabajo es una relación social de poder, y en su núcleo se expresa un conflicto inherente entre el titular del capital y los trabajadores.

Será, gracias en gran medida a Marx, que el sistema jurídico liberal deberá reconocer uno de sus secretos mejor guardados. Que atravesada la esfera de la circulación —ese "edén de los derechos innatos del hombre"donde trabajador y empleador se encuentran como portadores de mercancía, donde impera "exclusivamente la libertad, la igualdad, la propiedad y Bentham", ${ }^{47}$ hay poder y explotación.

En el interior de la fábrica recién desvelado, expuesto a la vista de todos, aparece el proceso de producción y una de sus más radicales consecuencias: la subsunción real del trabajador al capital. Como dijimos, la revolución derivada de la incorporación progresiva de tecnología — máquina de vapor y cadena de montaje_- y la resistencia colectiva del trabajo vivo a la extensión ilimitada de la jornada, se tradujo en la necesidad de someter radicalmente a la fuerza de trabajo al control del titular del capital.

El poder sobre el trabajador que aparecerá —una y otra vez- como el fundamento de la necesidad de protección del trabajador para los laboralistas

\footnotetext{
46 Ibidem, p. 75.

47 Marx, K., El capital, cit., p. 182.
} 
de Weimar. De hecho, es harto obvia la relación entre la idea de Marx de subsunción real y la de subordinación del derecho del trabajo. Como lo expone Kahn-Freund, en cuanto la idea de dependencia de Sinzheimer "es producto de la concepción de Marx y de su seguidor Renner, de que la propiedad capitalista implica una dominación sobre los seres humanos". ${ }^{48}$

Esa clave marxista permitirá, precisamente, a otros — como Korschformular una cita que acompaña el derecho del trabajo hasta nuestros días: "la libertad e igualdad de derecho de los contratantes se muestra como el simple disfraz ideológico de violencia brutal y descarnada que posee la relación de dominio en la que, bajo la vigencia ilimitada del principio del contrato libre de trabajo, cae inevitablemente el trabajador, apenas ha cruzado la puerta de la fábrica". ${ }^{49}$

Pero ese poder no es abstracto, sino concreto. Su objetivo es la producción de valor. Para ello requiere que la fuerza de trabajo medida por tiempo sea puesta al servicio de la producción de mercancías, lo que exige el menor salario para la mayor cantidad de trabajo posible.

Poder y explotación como dos caras de la misma moneda.

$\mathrm{Y}$, en fin, los autores de laboratorio Weimar son, antes que todo, berstenianos. Salvo Korsch, por supuesto. ${ }^{50}$

48 Kahn-Freund, O., Labour Law and Politics in the Weimar Republic, Oxford, Basil Blackwell, 1981, p. 79.

49 Korsch, K., Lucha de clases y derecho del trabajo, Barcelona, Ariel, 1980, p. 16.

50 Korsch es, pocas dudas caben, el más relevante laboralista marxista de la historia del derecho occidental hasta hoy. A diferencia de los que vendrán después, cuyas propuestas serán puramente crítica de la naturaleza mistificada del derecho laboral, su posición será eminentemente normativa y sostendrá una propuesta para la construcción de un genuino derecho del trabajo proletario. Para Korsch, la dirección de la historia de la acción proletaria en la regulación del trabajo es indefectiblemente transitoria y dialéctica: debe, primero, evolucionar de su versión burguesa, la del capitalismo liberal de fines del siglo XIX, a su versión social o sindical — la propia del capitalismo social de Weimar — y, después, a su versión revolucionaria o proletaria. Para en el final, en la consumación de la sociedad comunista, extinguirse. Se trata de un intento único dentro del pensamiento jurídico laboral occidental por construir un derecho del trabajo al margen de las relaciones de producción capitalistas. En su propuesta ha desaparecido el capitalista privado, quedan los trabajadores y la sociedad representada por el Estado, abriéndose dos formas de socialización: que la propiedad de la empresa pase al Estado (socialización indirecta) o a los trabajadores mismos (socialización directa). El derecho del trabajo proletario tiene que enfrentar dos dimensiones de la socialización del trabajo: el derecho de la ganancia de los trabajadores y el derecho de participación. Desde la perspectiva proletaria, ambas dimensiones no son equivalentes, en cuanto la regulación del derecho de la ganancia es una cuestión que califica de "técnica": ya sea que se trate de un salario — porque la propiedad está ahora en manos del Estado-, ya sea que se trate del reparto de utilidades — porque la propiedad 
Como dijimos, el laboratorio Weimar no era exactamente un espacio académico para el desarrollo de la dogmática jurídica sobre el derecho positivo. Antes que eso, era un núcleo de autores que ensayaron fórmulas y reflexiones sobre el derecho y el trabajo en las economías capitalistas, imbricados con su tiempo político e histórico, fórmulas que resistirían y se transformarían en las bases del derecho del trabajo, particularmente europeo, en la segunda mitad del siglo XX. ${ }^{51}$

Para que eso fuera posible, la constitución misma de un laboratorio de ideas jurídicas para ser puestas a prueba, se requería una condición política de posibilidad: la existencia de un espacio entre el liberalismo que había alimentado la imaginación burguesa en el siglo XIX y el marxismo ortodoxo que había surtido al movimiento obrero revolucionario en el mismo siglo.

La condición de posibilidad del laboratorio Weimar - y del futuro del derecho del trabajo que ese laboratorio imaginó- era plenamente política. Un espacio donde los trabajadores, dentro de los propios engranajes de la sociedad capitalista, pudieran ejercer el poder político que los votos y los hechos le otorgaban.

Y quien tendrá la llave para abrir ese espacio fue, precisamente, el albacea de Engels. En ese sentido, para que existiera un Sinzheimer, antes tuvo que existir un Bernstein.

paso a manos inmediatas de los propios trabajadores-, el problema para los trabajadores es el mismo: "se trata en realidad de hallar la solución necesariamente igual en cada caso de un mismo problema: qué parte del total de los beneficios debe ir a los productores en cuanto tales y qué parte debe ir a la colectividad”. Korsch, K., Escritos políticos, México, Folios, 1982, vol. 2, p. 15. No ocurre lo mismo con el derecho a la participación en la gestión de la producción por parte de los trabajadores. En esa dimensión del proceso de socialización, los trabajadores se juegan una idea clave del entramado político propuesto por Korsch: la democracia industrial y el consejo obrero. En sus palabras, "el camino de la realización a un tiempo segura y rápida de estas dos exigencias contenidas en el lema de la socialización, la de un control desde arriba (por la colectividad) y la de un control desde abajo (por los inmediatamente implicados en el proceso de producción) no es otro, hoy, que el representado por el tantas veces citado y tan escasamente comprendido "sistema de consejos". Id., cit., p. 24.

51 En la Inglaterra de principios de siglo veinte se había adelantado un litigio que décadas después se repetiría en la Alemania weimariana. La versión de un estatismo reformista donde el sindicato cumple un rol de defensa profesional en una producción organizada desde el Estado —la opción del fabianismo de los Webb- contra la articulación de una democracia productiva en torno a la idea de autogestión de los propios trabajadores — la opción de socialismo guildista de G.H.D Cole-. Años después éste será, en lo fundamental, el litigio que dividirá al laboratorio Weimar de los laboralistas: la opción del reformismo y la autonomía sindical dentro del contexto capitalista — la opción de Sinzheimer- contra la democracia de los consejos obreros - la opción de Korsch-. 
Su revisionismo será una forma de superar lo que se denominó la "crisis del marxismo", esto es, la cada vez más lejana posibilidad de que las predicciones del marxismo se cumplieran, y que las contradicciones del capitalismo - evolucionando científicamente- fueran a derribarlo. ${ }^{52}$

Frente a eso, Bernstein postulará la relevancia de la esfera política y la acción para transformar al Estado en beneficio de la clase obrera, lo que no exige indefectiblemente una revolución, sino la acción política dentro de la democracia parlamentaria para mejorar las condiciones de los trabajadores..$^{53}$ En sus palabras:

...la solidaridad se realiza en el seno del Estado a través de la lucha política. Y ésta sólo puede ser llevada por la clase obrera con el mayor éxito posible en la democracia.

La abolición de todo privilegio de clase: ése es el derecho político fundamental de la clase obrera. ${ }^{54}$

En ese sentido, la eliminación de la explotación de los trabajadores se producirá en la acción política institucional, mediante la obtención progresiva de poder político de la clase obrera, tanto a través de su mayor peso electoral, como de la creciente influencia política de los sindicatos. Es el camino abierto por Bernstein, para quien la revolución es un hecho que pierde relevancia, lo que se expresa en su conocida cita de "lo importante es el movimiento, no el fin".

52 Esa crisis "que constituirá el trasfondo de todos los debates marxistas desde finales del siglo XIX hasta la guerra, domina dos momentos fundamentales: la nueva conciencia de la opacidad de lo social, de las complejidades y resistencias de un capitalismo crecientemente organizado, y la fragmentación de los distintos agentes sociales que, según el paradigma clásico, deberían haber estado unidos". Laclau, E y Mouffe, Ch., Hegemonía y estrategia socialista. Hacia una radicalización de la democracia, Siglo XXI, Madrid, 1987, p. 43.

53 Bernstein entendía o quería entender que una forma de acreditar que Marx no era un revolucionario a secas, sino un "evolucionista revolucionario", es su opinión favorable sobre los sindicatos: "la posición respecto al sindicalismo ilustrada por la resolución de la Internacional que defendía con firmeza la organización sindical de los trabajadores. Y es que ya en fecha tan temprana como 1847, cuando casi todos los socialistas continentales se declaraban todavía enemigos mortales del sindicalismo, Marx había tomado partido por él". Bernstein, E., Karl Marx y la reforma social, Barcelona, Página Indómita, 2018, p. 76. Como se sabe, el punto es controvertible: hay en Marx citas tanto a favor, como en contra de los sindicatos en su relación con la emancipación de los trabajadores. Véase Hyman, R., El marxismo y la sociología del sindicalismo, México, Era, 1978.

54 Bernstein, E., El socialismo evolucionista, Comares, Granada, 2011, p. 129. 
El desafío que el socialismo evolutivo y revisionista de Bernstein planteaba a la ortodoxia marxista fue condensado, con precisión, por una de sus más célebres opositoras —Luxemburgo-:

...la teoría socialista se encuentra ante un dilema: o la revolución socialista sólo se concibe como resultado de las contradicciones internas del orden capitalista, contradicciones que aumentan al desarrollarse éste, haciendo del derrumbamiento algo inevitable, no importando el momento y forma en que se presente, pero que convierte en inútiles los medios de adaptación, siendo, por tanto, justa la teoría del derrumbamiento, o, por el contrario, esos medios de adaptación son capaces de evitar el hundimiento capitalista y de anular sus contradicciones, claro que cesando entonces el socialismo de ser una necesidad histórica, pudiendo ser luego todo lo que quiera, pero nunca el resultado del desarrollo material de la sociedad. Este dilema nos presenta a su vez otro: o el revisionismo tiene razón en cuanto al curso del desarrollo capitalista, siendo, por tanto, una utopía la transformación socialista de la sociedad, o el socialismo no es tal utopía, quedando entonces malparada la teoría de los medios de adaptación. That is the question. ${ }^{55}$

Se hace así cargo de la evolución del Estado capitalista, que había dado lugar - lenta pero progresivamente - a diversas reformas que mejoraban la posición social y económica de la clase obrera, particularmente en materia de seguro social y de leyes fabriles o laborales. Dicha legislación social de la segunda mitad del siglo diecinueve "no puede ser explicada principalmente por las necesidades regulatorias del capital o la estandarización de explotación capitalista", sino como espacio "que proporciona un área de interés común entre el capital y el trabajo", sentando "las bases racionales del moderno estado de bienestar". ${ }^{56}$

Dentro de esa esfera política, para ir progresivamente avanzando en la meta del socialismo, es clave, como revelará el propio Bernstein:

...desarrollar una legislación laboral que confiera al individuo mucha más seguridad, así como flexibilidad a la hora de escoger una ocupación. En ese sentido, las organizaciones más avanzadas de la economía, los grandes sindicatos, ya están mostrando la forma en que probablemente se desarrollarán

55 Luxemburgo, R., Reforma o revolución, Madrid, Akal, 2016, p. 13.

56 Gustafsson, B., "A New Look at Bernstein: Some Reflections on Reformism and History", Scandinavian Journal of History, vol. 3, 1978, p. 278. 
las cosas. Como hemos dicho, hay ya algunos indicios de que está surgiendo un sistema democrático de legislación laboral..$^{57}$

Subyacía en el fondo de las ideas berstenianas, la convicción ideológica de que el socialismo no era sino una profundización de las ideas liberales:

...el objetivo de todas las medidas socialistas, incluso aquellas que parecen ser medidas coercitivas, es el desarrollo y la protección de la personalidad libre. Un examen más detallado de las medidas siempre muestra que la coacción debatida incrementará la suma total de la libertad en la sociedad a un área más extensa, mayor libertad de la que resta. ${ }^{58}$

\section{Y agrega:}

...podríamos llamar al socialismo "liberalismo organizado", porque si examinamos más de cerca las organizaciones que el socialismo busca, y el modo en que las busca, encontraremos que lo que las distingue principalmente de las instituciones feudales en apariencia similares: no es otra cosa que su liberalismo: su constitución democrática y su apertura. ${ }^{59}$

El resultado será contundente y extremadamente sensible para lo que en el futuro se llamará derecho del trabajo. Puestos en palabras de Laclau y Mouffe: "Bernstein ve el problema desde el ángulo opuesto: el incremento del poder de la clase obrera, el desarrollo de la legislación social, y la 'humanización' del capitalismo están generando una 'nacionalización' de la clase trabajadora; el obrero ya no es sólo un proletario, también es un ciudadano". ${ }^{60}$

\section{Bernstein E., Karl Marx..., cit., p. 99.}

58 Bernstein, E., El socialismo..., cit., p. 96. Como se ve, Bernstein no andará descaminado en sus predicciones, y en el periodo posterior a las guerras mundiales, su proyecto será el triunfador en Europa y en buena parte de la tradición jurídico-político occidental. Por eso, nos dirá Hobsbawm: "en los principales países del capitalismo el modelo del movimiento obrero prevaleció en la edad de oro. Su victoria quedó simbolizada por el abandono formal del marxismo en el Programa de Godesberg de 1959 del Partido Socialdemócrata Alemán. Deshacerse del marxismo no parecía suponer pérdida alguna, a excepción de recuerdos sentimentales, porque cuando la edad de oro (1947-1973) tocó a su fin, los objetivos del reformismo se habían alcanzado en la práctica, y los obreros estaban incomparablemente mejor de lo que habrían podido imaginar incluso los más optimistas representantes de la reforma antes de 1914”. Hobsbawm, E., op. cit., p. 473.

59 Ibidem, p. 101.

60 Laclau, E. y Mouffe, Ch., op. cit., p. 67. 
Después de Bernstein, la emancipación de la clase obrera ya no será sólo cuestión únicamente revolucionaria. Será más bien, una cuestión de acción política progresiva y gradual dentro de los contornos de la misma sociedad capitalista, que presentará dos caras fundamentales: la política legislativa en favor de los trabajadores — cuya protohistoria corresponde a las leyes fabriles de limitación de jornada del siglo XIX - y la acción sindical como expresión de la organización de los trabajadores.

Los laboralistas de Weimar podrán caminar el horizonte abierto por Bernstein. En sus escritos hay profunda fe en la acción del Estado para la emancipación de los trabajadores: ya sea por la vía de la legislación laboral, ya sea por la vía de la autonomía colectiva. ${ }^{61}$

Poco tiempo después, Sinzhiemer podrá sostener que "los presupuestos para una actitud positiva de los trabajadores respecto del Estado y para el reconocimiento de los sindicatos como sus representantes calificados, fueron realizados a través del paso del Estado autoritario a la Constitución democrática", agregar que "la importancia de este hecho se ha podido manifestar plenamente sólo en el momento en que el Estado —dando cumplimiento

61 En rigor, la búsqueda de los antepasados políticos del derecho del trabajo no se detiene en Bernstein, sino que puede remontar a Lasalle. En efecto, la historia de la expansión del derecho del trabajo — de la mano de Weimar y sus laboralistas — habría sido políticamente impensable, sí años antes no se hubiera legitimado la acción del Estado en el espacio económico/productivo en protección de la clase que nacía —el proletariado- . Dicha legitimidad pudo ser posible no sólo por la teoría revisionista — la de Bernstein — a principios del siglo XX al interior del marxismo, sino por el espacio abierto en pleno siglo XIX por el llamado socialismo de Estado, concepción donde la figura clave será Ferdinand Lasalle. Famoso por sus reflexiones sobre la idea de Constitución —en su texto Qué es una Constitución - y con una controvertida relación con Marx —entre la amistad y la rivalidad—, Lasalle no verá al Estado como un instrumento irreversible de la dominación de la clase burguesa, sino "el principal valedor en la reivindicación de los derechos de la clase obrera, de modo que sin su apoyo no podría integrarse social ni políticamente. De ahí que el objetivo de ningún pueda consistir en destruir al único aliado posible, sino que, al contrario, la tarea principal sería conquistarlo", para dicho objetivo se "dispondría de una sola arma, el sufragio universal, la primera y fundamental reivindicación del movimiento obrero". Sotelo, I., Estado social, Madrid, Trotta, 2010, p. 168. Muerto joven, en duelo pasional, Lasalle —y su valoración reformista del Estado — será enfrentado por Marx, quien le dirigirá furibundos ataques a su legado en su famosa crítica al programa político del congreso del Partido Obrero Alemán, donde dirá en tono despectivo que "la organización socialista de todo el trabajo no resulta del proceso revolucionario de transformación de la sociedad, sino que 'surge' de 'la ayuda del Estado', ayuda que el Estado presta a las cooperativas de producción 'creadas' por él y no por lo obreros ¡Es digno de la fantasía de Lassalle eso de que con empréstitos se puede construir una nueva sociedad como se construye un ferrocarrill". Marx, K., "Crítica al programa de Gotha”, Antología, Buenos Aires, Siglo XXI, 2015, p. 453. 
a una promesa contenida en la carta constitucional del Reich- ha emprendido una obra de legislación social cuya realización era posible sólo con el sustento de la participación de los trabajadores y sus organizaciones que estuviesen integradas en el Estado". ${ }^{62}$

La síntesis perfecta de la herencia de Bernstein en la ideología políticojurídica del laboralismo de Weimar, y de ahí en buena parte del derecho del trabajo hasta nuestros días, será perfilada por Kahn Freund: “el ordenamiento jurídico no niega ni sofoca la lucha de clases, pero no le concede tampoco una libertad ilimitada. En vez de eso, intenta delinear, con sus normas jurídicas, las modalidades de desarrollo en el ámbito del sistema capitalista", y mantener "una cierta afinidad entre un ordenamiento jurídico de índole colectiva y un sistema de libre competencia. Ambos parten de la misma premisa: que en el seno del ordenamiento jurídico tiene lugar un conflicto, y que tal conflicto (entendido un contraste entre partes que, disponiendo de una fuerza potencialmente equivalente, tienen chances potencialmente iguales) produce un resultado susceptible de reglamentación jurídica", lo cual constituye como presupuesto fundamental "la subsistencia de un cierto equilibrio entre la clase obrera y la trabajadora". ${ }^{63}$

La máxima expresión concreta e institucional de esas ideas sería, pocas dudas caben, la Constitución de 1919 y su constitucionalización del derecho del trabajo. Más específicamente de su versión weimariana: protección constitucional al trabajo (artículo 157), establecimiento del derecho del trabajo (artículo 163), reconocimiento de los sindicatos y su libertad (artículo 159), reconocimiento de la negociación colectiva y del rol de los consejos obreros (165). ${ }^{64}$

62 Sinzheimer, H., "La democratización de la relación de trabajo", La lucha por el nuevo..., cit., p. 139. La idea tan relevante para Sinzheimer de la autonomía colectiva como expresión de la autodeterminación social no debe ser leída como una forma jurídica incompatible con el Estado. Al revés, existe una potencial concordancia entre ambas, ya que puestas en sus propias palabras supone que "la regulación de las relaciones laborales no ha de ser sólo producto del derecho estatal, sino que tiene que ocurrir, además, mediante la autodeterminación social. Poder y alcance de esta autodeterminación social, cuya esencia en la regulación autónoma de las relaciones laborales mediante las fuerzas socialmente organizadas, crece constantemente". El Estado, dirá tajantemente, "no debe poner trabas a este desarrollo, sino que tornarlo fecundo". Su tarea es poner a disposición las necesarias formas jurídicas en que puede realizarse la voluntad de la autodeterminación social. Sinzheimer, H., "La reorganización del derecho del trabajo", La lucha por el nuevo..., cit., p. 73.

63 Kahn-Freund, O., "Il mutamento della funzione del diritto del lavoro", en varios autores, Laboratorio Weimar, Arrigo y Vardaro (eds.), Roma, Lavoro, 1982, p. 232.

64 Los consejos obreros de la Constitución de Weimar no son, por supuesto, los propios del sistema concejil, propuestos por la teoría revolucionaria del movimiento obrero. Como 
Pocas dudas caben, en fin, de que en esas claves filosóficas quedará determinado el espacio en que se moverá la mejor versión del derecho del trabajo hasta el día de hoy: la relevancia del trabajo como modo de realización humano (Hegel), el contexto conflictivo en que se desenvuelve en las sociedades capitalistas debido a la explotación y poder que se ejerce sobre los trabajadores (Marx), y la necesidad de protegerlos a través de la acción del Estado y del reconocimiento de sus propias organizaciones (Bernstein).

\section{BIBLIOGRAFÍA}

Anderson, P., "Las limitaciones y las posibilidades de la acción sindical", Pensamiento Crítico, Habana, núm. 13, 1968.

Anderson, P., Consideraciones sobre el marxismo occidental, Madrid, Siglo XXI, 2017.

ARENDT, H., Karl Marx y la tradición del pensamiento politico occidental, Madrid, Encuentro, 2008.

ARendt, H., Sobre la revolución, Madrid, Alianza, 2017.

BERnSteIn, E., Karl Marxy la reforma social, Barcelona, Página Indómita, 2018.

BERNSTEIN, E., El socialismo evolucionista, Granada, Comares, 2011.

BOnsiePen, W., 'Introducción', en HEGEL, G. W. F., Fenomenología del espiritu, México, Fondo de Cultura Económica, 2017.

CHICCHI, F. et al., Más allá del salario, Madrid, Enclave, 2018.

DOMÈNECH, A., El eclipse de la fraternidad, Madrid, Akal, 2019.

aclara el propio Sinzheimer, estos últimos y su función política equivalen a una dictadura incompatible con el régimen democrático que se consagra constitucionalmente: "es suficiente afirmar en esta sede que una tal dictadura de los consejos se pondría en contraste con la democracia y que en nuestro tiempo es necesario entre dictadura de una minoría y democracia, o sea, el gobierno de la mayoría. La asamblea constituyente, como ya la mayoría del pueblo, se ha expresado por la democracia", Sinzheimer, H., "Relazione all'assemblea costituente", en varios autores, Laboratorio Weimar, cit., p. 46. Esa concepción del consejo como una forma más inofensiva políticamente, será estructurada en la República de Weimar por la Ley de Consejos —1920—: "la ley sobre las relaciones laborales legalizó los consejos existentes únicamente a nivel de taller. Les permitió representar las demandas de los trabajadores, pero no ejercer control alguno sobre la producción [...] como resultado, los consejos de taller de la recién nacida República alemana se convirtieron en órganos subalternos e impotentes, reducidos básicamente a los mismos derechos que los consejos de taller de la Alemania actual". Hoffrogge, R., op. cit., p. 145. 
Fromm, E., Marx y su concepto del hombre, Fondo de Cultura Económica, México, 2016.

Gargarella, R., La sala de máquinas de la Constitución. Dos siglos de constitucionalismo en América Latina (1810-2010), Buenos Aires, Katz Editores, 2014.

GIL, R., El derecho del trabajo democrático en la República de Weimar, Albacete, Bomarzo, 2017.

Gramsci, A., Antología, México, Siglo XXI, 2010.

Gustafsson, B., "A New Look at Bernstein: Some Reflections on Reformism and History", Scandinavian Journal of History, vol. 3, 1978.

Hegel, G. W. F., Fenomenología del espiritu, México, Fondo de Cultura Económica, 2017.

HePPle, B., "Introducción”, en VARIOS AUTORES, La formación del derecho del trabajo en Europa, Madrid, Ministerio del Trabajo y Seguridad Social, 1994.

Herrera, C. M., "El constitucionalismo social weimariano en el pensamiento francés entreguerras", Historia Constitucional, Madrid, Centro de Estudios Políticos y Constitucionales, núm. 20, 2019.

Hobsbawm, E. Cómo cambiar el mundo, Buenos Aires, Crítica, 2011.

Hobsbawm, E. Revolucionarios, Madrid, Crítica, 2010.

Hoffrogge, R. "Del sindicalismo a los consejos obreros", en VARIOS AUTORES, Poder obrero: controly autogestión obrera, Madrid, La Oveja Roja, 2017

HorkHeimer, M., "La impotencia de la clase obrera alemana", Ocaso, Madrid, Taurus, 1986.

Hyman, R., El marxismo y la sociología del sindicalismo, México, Era, 1978.

KAHN-FrEUND, O., "Il mutamento della funzione del diritto del lavoro", en VARIOS AUTORES, Laboratorio Weimar, ARRIGO y VARDARO (eds.), Roma, Lavoro, 1982.

KAhn-Freund, O., Labour Law and Politics in the Weimar Republic, Oxford, Basil Blackwell, 1981.

KonsCH, K., Lucha de clases y derecho del trabajo, Barcelona, Ariel, 1980.

LACLAU, E. y MOUFFE, Ch., Hegemonía y estrategia socialista. Hacia una radicalización de la democracia, Madrid, Siglo XXI, 1987.

LOFFREDO, A., "La identificación entre contrato y trabajo en los orígenes y en la actualidad del derecho italiano", Revista Derecho Social, Alicante, Bomarzo, núm. 68, 2014.

Luxemburgo, R., La Comuna de Berlín, México, Grijalbo, 1971. 
LuXEMbuRgo, R., Reforma o revolución, Madrid, Akal, 2016.

MARCuSE, H., Razón y revolución, Madrid, Alianza, 2015.

Marx, K., El capital, Santiago, Lom, 2010.

MarX, K., El capital, Libro I, capítulo VI (inédito), México, Siglo XXI, 2015.

MARX, K., "Crítica al programa de Gotha", Antología, Buenos Aires, Siglo XXI, 2015.

MEDA, D., El trabajo: un valor en extinción, Barcelona, Gedisa, 1998.

NeGRI, T., Marx y Foucault, Buenos Aires, Cactus, 2019.

PannekoeK, A., Crítica del bolchevismo, Barcelona, Anagrama, 1976.

PINTO, J., Luis Emilio Recabarren: una biografía bistórica, Santiago, Lom, 2013.

POLANYI, K., La gran transformación, México, Fondo de Cultura Económica, 2001.

Poulzantas, N., Estado, poder y socialismo, México, Siglo XXI, 2014.

READ, J., La micropolitica del capital, Madrid, Tierra de Nadie Ediciones, 2016.

SAYERS, S., "The Concept of Labor: Marx and his Critics", Science and Society, vol. 71, núm. 4, octubre de 2007.

SILVER, B., Fuerzas del trabajo: los movimientos obreros y la globalización desde 1870, Madrid, Akal, 2005.

SinZHEIMER, H., Crisis económica y derecho del trabajo. Cinco estudios sobre la problemática bumana y conceptual del derecho del trabajo, Madrid, Ministerio del Trabajo y Seguridad Social, 1984.

SinZHEIMER, H., La lucha por el nuevo derecho del trabajo, Valparaíso, Edeval, 2017.

TRONTI, M., Obreros y capital, Madrid, Akal, 2001.

VARIOS AUTORES, Laboratorio Weimar, ARRIGO y VARDARO (eds.), Roma, Lavoro, 1982.

VENEZIANI, B., "La evolución del contrato de trabajo", en VARIOS AUTORES, La formación del derecho del trabajo en Europa, Madrid, Ministerio del Trabajo y Seguridad Social, 1994.

VICENTE, C. de, La revolución de 1918-1919. Alemania y el socialismo radical, Madrid, Catarata, 2018.

VITA, L., "Constitucionalismo social como democracia económica. Una relectura de la Constitución de Weimar a la luz del aporte de Hugo Sinzheimer", Historia universal, Centro de Estudios Políticos y Constitucionales, núm. 19, 2018. 
WALlis, V., "Control obrero y revolución", en VARIOS AUTORES, Poder obrero, Madrid, La Oveja Roja, 2017.

WEBB, S. y WEBB, B., La democracia industrial, Madrid, Fundación Largo Caballero, 2004.

WeITZ, E., La Alemania de Weimar. Presagio y tragedia, Madrid, Turner, 2009. 